\title{
Viewpoints
}

\section{Global surgery research collaborations during the COVID-19 pandemic}

\author{
Anisa Nazir', Ramya Kancherla² $\odot \otimes$, Bright Huo ${ }^{3}$, Brintha Sivajohan ${ }^{4}$, Shaishav Datta ${ }^{5}$, Amanpreet Brar ${ }^{6}$, Ayesha \\ Tasneem ${ }^{7}$ \\ 1 Institute of Medical Sciences, Institute of Medical Sciences, University of Toronto, ON, Canada; Foundation University Medical College, Islamabad, \\ Pakistan, ${ }^{2}$ Department of Surgery, McMaster University, Hamilton ON, Canada, ${ }^{3}$ Faculty of Medicine, Dalhousie University, Halifax NS, Canada, 4 \\ Schulich School of Medicine and Dentistry, Western University, London, ON, Canada, 5 Temerty Faculty of Medicine, University of Toronto, Toronto, \\ ON, Canada, ${ }^{6}$ Department of Surgery, University of Toronto, Toronto, ON, Canada, 7 Department of Surgery, University of Calgary, Calgary ON \\ Canada
}

Keywords: global surgery, research, collaboration, covid-19

https://doi.org/10.52872/001c.29066

\section{Journal of Global Health Economics and Policy}

Vol. 1, 2021

\begin{abstract}
The COVID-19 pandemic created an unprecedented burden on health systems, including surgical services, which have been indirectly affected by the growing number of cases due to cancellation of operations, delayed screening and a lack of adequate resources such as PPE and ventilators. In addition to logistical challenges, the pandemic also raised imminent clinical questions that required immediate answers. Global collaborations have been vital to identifying challenges by pooling data and collecting evidence to provide critical information to guide clinical and surgical care. Research partnerships have been the driving force behind global surgery research; however, since the pandemic, there has been an increased need for equitable collaboration and innovation between high-income and low-income research institutions to continue making steady progress towards providing access to safe, affordable surgical care. This article explores academic research partnerships formed during the pandemic and identifies challenges and opportunities presented to researchers and institutions. Finally, this paper recommends that further collaborations be made between HIC and LMICs to ensure policies that global surgery ensures that key stakeholders are at the centre of research. Such policies need to focus on the access to education and mentorship, micro-grants for researchers, and publication opportunities.
\end{abstract}

The COVID-19 pandemic created an unprecedented burden on health systems, including surgical services, which have been indirectly affected by the growing number of cases due to cancellation of operations, delayed screening and a lack of adequate resources such as PPE and ventilators. ${ }^{1}$ In addition to logistical challenges, the pandemic also raised imminent clinical questions that required immediate answers. Global collaborations have been vital to identifying challenges by pooling data and collecting evidence to provide critical information to guide clinical and surgical care. Research partnerships have been the driving force behind global surgery research ${ }^{2}$; however, since the pandemic, there has been an increased need for equitable collaboration and innovation between high-income and low-income research institutions to continue making steady progress towards providing access to safe, affordable surgical care. This article explores academic research partnerships that have been formed during the pandemic, identifies challenges and opportunities presented to researchers and institutions and provides recommendations for future collaborations.

There are many well-documented limitations for research in low-resource settings; some barriers cited preCOVID-19 included lack of human resources, financial con- straints, poor connectivity, and difficulty accessing records. ${ }^{2,3}$ Constraints around regulatory requirements at the hospital and national levels, such as the inability to access ethical approvals, also prevented research activities. Language is another cited barrier as publishing in English improves visibility and citation results. ${ }^{3}$ In turn, it discourages trainees and researchers who otherwise may not have the resources or ability to publish in the English language. In LMICs, surgical researchers' time is limited as they are involved in other roles such as administration, education and expansion of surgical programs in their local communities. $^{2}$ It is difficult for junior researchers to find established research mentors and guidance. Access to academic education in LMICs is also a barrier in training researchers. Obtaining academic degrees is often expensive, and many HIC educational institutions have additional fees and additional costs of living abroad for international students that can deter future scientists and researchers. Academic affiliations provide access to other researchers' networks for potential collaboration and provide resources such as library access and technologies for future projects inaccessible by LMIC researchers.

The pandemic has added to the limitations of the underdeveloped research systems in LMICs. In-person global 
surgery research in HICs and LMICs has been operating at a limited capacity due to extensive lockdowns. Travel restrictions have drastically changed the way relationships are developed and maintained with local partners, and international collaborations that rely on these exchanges may be at risk. Similarly, human resources encounter additional limitations due to the high clinical burden of COVID-19 and the need for surgical researchers to shift to clinical duties. As high-income partners redirected funds for pandemic preparation and management rather than global surgery initiatives, funding limitations are also a hurdle. Access to the internet is limited in many LMICs, and in addition, prevalent political unrest may led to internet shutdowns in many countries in Africa and South America, causing disruptions in participating in research meetings and presenting at virtual conferences. ${ }^{4}$ Recognizing these challenges and investing in research and development in LMICs is essential to improving health systems.

Clinical research drives improvement in patient outcomes; however, most research is conducted in high-income settings with limited generalizability to LMICs. ${ }^{5}$ While distance has traditionally been a barrier to conducting effective global surgery research, the introduction of online platforms and their acceleration during the pandemic to complete work, meetings, conferences, and networks have created an ideal global environment for researchers in this field. ${ }^{6}$ Benefits of this adaptation include time and cost savings associated with travel and increased flexibility in schedules. ${ }^{6}$ As a consequence, the virtual presence of academics in medicine has never been stronger. For example, CovidSurg, succeeded by GlobalSurg, is a platform of studies created to explore the impact of COVID-19 in surgical patients, creating a collaborative network of over 112 countries, 1566 centres and 116,500 patients (Table 1 ). Early topics explored to date include the timing of surgery in COVID-19 positive patients, mortality and pulmonary complications among COVID-positive patients undergoing surgery, and the impact of COVID-19 on cancer patients. ${ }^{1,7,8}$ Findings from these studies have led to pandemic preparedness plans and adoption of "COVID-19 free surgical pathways" to provide safe surgical care to patients. In addition, it has contributed to informing best practices, guidance for patients and patient safety globally. 1,7,8 Further examples of such global surgery collaborations are highlighted in Table 1. These global collaborations have been immensely impactful in addressing imminent clinical questions promptly and shaping surgical care globally during the pandemic.

One way to improve research capacity in low-resource settings is to provide education for junior trainees who can lead research projects. Novel methods of communication have become commonplace, and as such, our virtual climate's acceptability has improved our connectedness to some of the world's most remote geographic areas. ${ }^{6}$ This has improved our ability to perform and disseminate research on a global scale and increased accessibility of education. Free, centralized resources such as SICOT-PIONEER, a virtual platform hosting a series of surgical webinars, are being created with increasing frequency to share virtual education, research and resources in global surgery topics. $^{6,9}$ Access to educational resources will be key to train the workforce in LMICs that can conduct high-quality research and ask key questions that drive interventions and their implementation, tailored to their particular environments and needs. As previously mentioned, the lack of research capacity and access to local research funds for junior researchers is a significant deterrent for junior researchers in LMICs. They are often the best suited to identify priority issues, understand local needs to complete high-quality research. Micro-grants have been used previously to develop programs in LMICs, but could also be translated to global surgery collaborations either in the form of micro-grants or the division of larger grants into smaller funding pools. For example, micro-grants have been used in emergency medicine in areas where the speciality has not been yet established and have been shown to facilitate research in a developing setting. ${ }^{10}$ In addition, collaborative initiatives can impact innovation and provide incentives for organizations to partner with LMICs. For example, one recent network analysis revealed that robotic surgery has a global network of 1700 organizations with 6000 connections and can reach many international networks. ${ }^{6,11}$ This increased connectedness has implications for potential stakeholders such as policy-makers and industry to develop plausible international research and innovation strategies and provide agency to academic institutions in LMICs.

To continue to make research a priority in LMICs, we must ensure that collaborators have access to resources to initiate research and protocol development so that relevant surgical quality improvement questions can be prioritized. There is mutual benefit to collaborations between individuals from HICs and LMICs, including knowledge gain and translation, development of skills, shared innovation, and improved health systems. However, there are differences in the priorities between HICs and LMICs. For example, one collaboration exercise demonstrated that the chosen topics for research, in what was deemed fundamental surgical patient needs, drastically differed between HIC and LMIC collaborations. ${ }^{5}$ Variations in infrastructure, resources, disease burden, and financial planning can account for some of the difference in research priorities between the two groups. One way to ensure potential research priorities are not overlooked includes using surveillance tools that engage LMIC clinicians and surgeons to document priorities and problems pertinent to their practices and hospitals. ${ }^{6}$ This will allow for a mutually beneficial relationship and collaboration between both HIC and LMIC partners.

Ensuring that LMIC collaborators have the appropriate support and are connected to the stakeholders will also help create sustainability for research collaborations during the pandemic and ensure that diverse multidisciplinary teams are formed to develop impactful research that informs clinical practice. Moreover, the shift to virtual care models may make it easier for LMIC clinicians to connect with global stakeholders. However, the potential lack of telecommunication and digital network infrastructure in the Global South must be considered when planning collaborations during the pandemic. ${ }^{4}$ Shared virtual drives will make collaboration smoother and allow for feedback to be more easily collected and disseminated to all team members. If virtual meeting and collaboration platforms are unavailable or inaccessible to LMIC collaborators, clinicians and trainees, 
researchers should explore obtaining these resources as they present a longitudinal investment that can be utilized well past the pandemic. ${ }^{6}$ Collaborations can also provide opportunities for academic pathways for scientists to pursue research in LMICs with academic recognition. Similarly, academic collaborative projects can help shift global surgery research hubs to institutions in LMICs where these projects are established and develop a grassroots research workforce. Finally, the policy at the national level in LMICs and international bodies should encourage ownership of surgical research and funding to allow LMIC partners to prioritize their needs and improve health systems.

Global surgery collaborations are still significantly developing, and research is an area that is highly underrepresented with global surgery. It is due to multiple factors, including the novelty of the field, lack of funding and researchers, a heavy HIC focus, and journal limitations. The importance of global surgery research in LMICS is self-evident and provides an avenue to identify gaps in care, possible areas of improvement, and better understand the context in which global surgery operates. The policy should be developed to ensure LMIC centred research through access to education and mentorship, micro-grants for junior researchers, publication opportunities, and increased collaborations between HIC and LMICs to ensure that global surgery is not opportunistic that key stakeholders are at the centre of research. For global surgery research to be successful, it requires strong collaborations between parties in HIC and LMIC countries to be fostered. COVID-19 has displayed an opportunity to better develop research in global surgery by increasing the accessibility of virtual meetings and collaborations. Moving forward, these platforms can be used to help strengthen networks as well as develop stronger equity in global surgery.

\section{FUNDING}

No funding was obtained for this study.

\section{CONFLICT OF INTERESTS}

The authors completed the ICMJE Unified Competing Interest form (available upon request from the corresponding author), and declare no conflicts of interest.

\section{AUTHORS' CONTRIBUTIONS}

All authors have contributed to each stage of the manuscript design and preparation, and approved the final version. All authors agree to be accountable for all aspects of the work.

\section{AUTHORS’ INFORMATION}

All authors are members of the Canadian Global Surgery Trainees Alliance which is a national global surgery organization in Canada, affiliated with the International Student Surgical Network.

\section{CORRESPONDENCE}

Ramya Kancherla, McMaster University, 711 Concession Street Hamilton, ON, Canada L8V 1C3; phone: +1 (905) 536-4848; ramya.kancherla@medportal.ca

Submitted: September 29, 2021 CET, Accepted: October 07, 2021 CET 


\section{REFERENCES}

1. COVIDSurg Collaborative, Bhangu A, Lawani I, et al. Global guidance for surgical care during the COVID-19 pandemic. Br J Surg.

2020;107(9):1097-1103. doi:10.1002/bjs.11646

2. Hedt-Gauthier BL, Riviello R, Nkurunziza T, Kateera F. Growing research in global surgery with an eye towards equity. Br J Surg. 2019;106(2):e151-e155. doi:10.1002/bjs.11066

3. Global Surgery doesn't belong to the English Language Available from. Blogs BGH. 2019. https://blo gs.bmj.com/bmigh/2019/04/18/global-surgery-doesn t-belong-to-the-english-language/?fbclid=IwAR0WT KgprphOZUi61-nDq9cHXkf1ExozZJXJe8fanly 4yL69I Xb4UcMltE. Accessed February 16, 2021.

4. Joos E, Zivkovic I, Shariff F. Virtual learning in global surgery: Current strategies and adaptation for the COVID-19 pandemic. IJS Global Health. 2021;4(1):e42-e42. doi:10.1097/gh9.00000000000000 $\underline{42}$

5. Nepogodiev D, Moore R, Biccard B. Prioritizing research for patients requiring surgery in low- and middle-income countries. British Journal of Surgery. 2019;106(2):e113-e120. doi:10.1002/bjs.11037

6. Scarlat MM, Sun J, Fucs PMB, et al. Maintaining education, research and innovation in orthopaedic surgery during the COVID-19 pandemic. The role of virtual platforms. From presential to virtual, front and side effects of the pandemic. Int Orthop. 2020;44(11):2197-2202. doi:10.1007/s00264-020-048 $\underline{48-8}$
7. Nepogodiev D, Bhangu A, Glasbey JC, et al. Mortality and pulmonary complications in patients undergoing surgery with perioperative SARS-CoV-2 infection: An international cohort study. The Lancet. 2020;396(10243):27-38. doi:10.1016/s0140-6736(20)3 $\underline{1182-\mathrm{x}}$

8. Glasbey JC, Nepogodiev D, Simoes JFF, et al. Elective Cancer Surgery in COVID-19-Free Surgical Pathways During the SARS-CoV-2 Pandemic: An International, Multicenter, Comparative Cohort Study. JCO. 2021;39(1):66-78. doi:10.1200/jco.20.0193 $\underline{3}$

9. COVIDSurg Collaborative, Glasbey JC, Nepogodiev $\mathrm{D}$, et al. Delaying surgery for patients with a previous SARS-CoV-2 infection. Br J Surg.

2020;107(12):e601-e602. doi:10.1002/bjs.12050

10. Hallas P, Brabrand M, Folkestad L. Microfinance as a method of facilitating research in emergency medicine. Scand J Trauma Resusc Emerg Med. 2010;18(1):23. doi:10.1186/1757-7241-18-23

11. Garas G, Cingolani I, Patel V, et al. Surgical Innovation in the Era of Global Surgery: A Network Analysis. Ann Surg. 2020;271(5):868-874. doi:10.109 7/sla.0000000000003164 


\section{APPENDIX}

Table 1. International Collaborations in Global Surgery during the COVID-19 Pandemic.

\begin{tabular}{|c|c|c|}
\hline Collaboration & Partners & Description \\
\hline $\begin{array}{l}\text { Global Surg I COVID Surg Week } \\
\text { https://globalsurg.org/covidsurg/ } \\
\text { CovidSurg Cohort Study } \\
\text { https://globalsurg.org/ } \\
\text { covidsurgcohortstudy/ } \\
\text { Covid-Surg Cancer } \\
\text { https://globalsurg.org/ } \\
\text { cancercovidsurg }\end{array}$ & $\begin{array}{l}\text { CovidSurg Collaborative: a collaborating group } \\
\text { of researchers in } 112 \text { countries, } 1566 \text { centres, } \\
\text { and } 116500 \text { patients as of January 1st, } 2021 .\end{array}$ & $\begin{array}{l}\text { An international prospective multi- } \\
\text { centre cohort study investigating } \\
\text { the optimal timing of surgery } \\
\text { following SARS-CoV-2 infection } \\
\text { and assessing key global surgical } \\
\text { indicators such as postoperative } \\
\text { mortality. } \\
\text { An international multi-centric } \\
\text { cohort study assessing } 30 \text {-day } \\
\text { mortality in surgical patients with } \\
\text { SARS-CoV2 infection. } \\
\text { An international cohort study } \\
\text { assessing the safety of surgery for } \\
\text { all types of cancer during the } \\
\text { COVID-19 pandemic and the } \\
\text { impact of the pandemic in cancer } \\
\text { delay and treatment pathways }\end{array}$ \\
\hline $\begin{array}{l}\text { CovidPaedsCancer } \\
\text { https://mailchi.mp/d36e35d79b57/ } \\
\text { exciting-beginnings-global- } \\
\text { childrens-ncds- } \\
\text { newsletter-2784946?e=8eb56c4a2f }\end{array}$ & $\begin{array}{l}\text { Various international organizations facilitated } \\
\text { by the Global Children NCDs group for } 1065 \\
\text { Collaborators in } 362 \text { centres as of January 1st, } \\
2020 \text {. }\end{array}$ & $\begin{array}{l}\text { An international, multi-centre } \\
\text { study to assess the impact of the } \\
\text { COVID-19 pandemic on pediatric } \\
\text { cancer services and their outcomes } \\
\text { globally }\end{array}$ \\
\hline $\begin{array}{l}\text { COMPASS (Management of } \\
\text { COMPlicAted intra-abdominal } \\
\text { collectionS after colorectal Surgery) } \\
\text { Study } \\
\text { https://starsurg.org/ } \\
\text { compass-2019-20/ }\end{array}$ & $\begin{array}{l}\text { EUROSurg and STARSurg collaboration in both } \\
\text { the UK and Ireland }\end{array}$ & $\begin{array}{l}\text { A study exploring the management } \\
\text { of complicated intra-abdominal } \\
\text { collections after colorectal surgery. }\end{array}$ \\
\hline $\begin{array}{l}\text { The COVID Stones Collaborative: } \\
\text { How has the Management of } \\
\text { Ureteric Stones Changed During } \\
\text { and After the COVID-19 Pandemic? } \\
\text { https://www.covidstones.org/ }\end{array}$ & $\begin{array}{l}\text { Collaboration between } 85 \text { centres and over } 220 \\
\text { collaborators in the UK as of January 1st, } 2020 .\end{array}$ & $\begin{array}{l}\text { The COVID Stones study is a } \\
\text { multicenter national cohort study } \\
\text { of patients' management and } \\
\text { outcomes with ureteric stones } \\
\text { before, during, and after the } \\
\text { COVID-19 pandemic in the United } \\
\text { Kingdom. }\end{array}$ \\
\hline $\begin{array}{l}\text { SICOT-PIONEER (Programme of } \\
\text { Innovative, Orthopaedic } \\
\text { Networking, e-learning, Education \& } \\
\text { Research } \\
\text { https://www.sicot.org/pioneer }\end{array}$ & $\begin{array}{l}\text { SICOT (Société Internationale de Chirurgie } \\
\text { Orthopédique et de Traumatologie), is an } \\
\text { international association promoting the } \\
\text { advancement of orthopaedics and } \\
\text { traumatology at an international level. SICOT } \\
\text { PIONEER is the latest initiative by SICOT's } \\
\text { Education Academy. }\end{array}$ & $\begin{array}{l}\text { Since June } 2020 \text {, this virtual } \\
\text { platform has hosted a series of } \\
\text { webinars, and it is currently } \\
\text { planning different e-events ranging } \\
\text { from podcasts to live-streamed } \\
\text { surgical demos. }\end{array}$ \\
\hline
\end{tabular}

